\title{
Optimization of the level of thermal insulation of enclosing structures of civil buildings
}

\author{
Jurgis Zemitis ${ }^{1}$, Maxim Terekh ${ }^{2 *}$ \\ ${ }^{1}$ Riga Technical University, Department of Heat and Gas technology, Riga, Latvia \\ ${ }^{2}$ Peter the Great St. Petersburg Polytechnic University, Polytechnicheskaya 29, St. Petersburg, \\ 195251, Russian Federation
}

\begin{abstract}
In the work, methods of an estimation of economic efficiency of additional heat insulation of building enclosing structures and definition of an optimum thermal resistance are considered, deficiencies of the given techniques are marked. A model is proposed for determining the optimal level of heat protection in the new economic conditions.
\end{abstract}

\section{Introduction}

The problem of energy saving is a topic of current interest in many countries of the world. A considerable amount of energy is consumed by residential and civil buildings due to the low thermal properties of the building envelope. To increase the thermal resistance of the enclosing structures, a large number of structural concepts are being developed using various materials $[7,11,12]$. To make the best decision on the installation of additional thermal insulation in different countries, there are various methods for assessing the economic efficiency of a design solution for thermal insulation[7].

In the former GDR, when choosing the optimal solution for the walls of reconstructed buildings, the following indicators were used [1]:

- the ratio of one-time costs to the annual energy savings of the heating system due to the thermal insulation device, F coefficient;

- the ratio of reduced costs to the annual energy savings of the heating system;

- relation of one-time costs to reduced costs.

The first of the indicators is the main one. To determine its one-time costs $n$ is calculated by the formula:

$$
\mathrm{n}=\mathrm{a}_{\mathrm{o}}+\mathrm{a}_{\mathrm{i}} \cdot \Delta \mathrm{R},
$$

where $a_{i}$ - coefficient proportional to the cost of insulation;

$a_{o}$ - part of the cost, which is determined by a constructive solution and does not depend on the thickness of the insulation layer (takes into account the cost of fixing, the base for plaster, etc.);

\footnotetext{
* Corresponding author: m_terekh@mail.ru
} 
$\Delta \mathrm{R}$ - improvement of thermal resistance of the building envelope by the introduction of additional thermal insulation.

According to the methodology developed by the specialists of the Graduate School of Architecture and Construction in Weimar, the annual energy costs for heating the building are calculated according to the formula:

$$
\mathrm{E}=\frac{\Delta \theta \cdot \mathrm{b}}{\mathrm{R}}
$$

where $\Delta \theta$ - the calculated difference between the temperature of the outside and the inside air;

$\mathrm{b}$ - the duration of the heating period.

Given the above formulas, the expression for the index $\mathrm{F}$ gets the form:

$$
F=\frac{\left(a_{0}+a_{i} \cdot \Delta R\right) \cdot R_{1} \cdot R_{2}}{\Delta R \cdot \Delta \theta \cdot b} .
$$

To select the optimal option for additional thermal insulation of fences, several technical solutions are developed with different insulation thickness. The minimum value of the index $\mathrm{F}$ determine the most effective design with optimal thermal resistance (Figure. 1.).

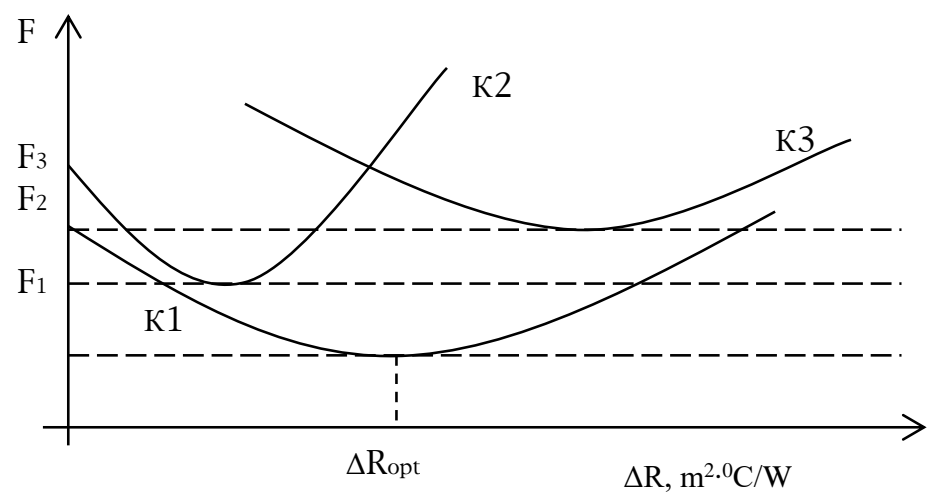

Fig.1. Dependence of the cost indicator $F$ on the thermal resistance $\Delta R$ of the layer of effective insulation for three design solutions.

According to the methodology developed in Germany [1], the payback period and profitability ratio $\mathrm{A}$ is used as criteria for economic efficiency, which is the ratio of annual savings to compensate for heat losses through $1 \mathrm{~m}^{2}$ of wall area $-\Delta \mathrm{K}_{\mathrm{B}}$ to one-time costs for improving insulation $1 \mathrm{~m}^{2}$ of $\Delta \mathrm{K}_{\mathrm{i}}$ :

$$
\mathrm{A}=\frac{\Delta \mathrm{K}_{\mathrm{B}}}{\Delta \mathrm{K}_{\mathrm{i}}}
$$

The optimal design will be considered, for which the coefficient of profitability A will be equal to the maximum. 
$\Delta \mathrm{K}_{\mathrm{B}}$ is determined by the formula:

$$
\Delta \mathrm{K}_{\mathrm{B}}=\frac{8,64 \cdot \Delta \mathrm{K}_{\mathrm{m}} \cdot \mathrm{G} \cdot \mathrm{K}_{\mathrm{e}}}{100 \cdot \eta \cdot \mathrm{H}_{\mathrm{u}}}
$$

where $\Delta \mathrm{K}_{\mathrm{m}}$ - the difference of heat transfer coefficients of the non-insulated and heatinsulated structure;

$\mathrm{G}$ - the number of heating degrees-hours;

$\eta$ - efficiency heating system;

$\mathrm{H}_{\mathrm{u}}$ - the lowest calorific value of the fuel.

The formula for determining one-time costs is:

$$
\Delta \mathrm{K}_{\mathrm{i}}=\mathrm{d} \cdot \mathrm{K}_{\mathrm{i}}+\mathrm{K}_{\mathrm{a}}
$$

where $\mathrm{K}_{\mathrm{a}}$ - constant part of one-time costs;

$\mathrm{d}$ - the thickness of the insulation layer;

$\mathrm{K}_{\mathrm{i}}$ - the unit cost of insulation thickness.

The optimal thickness of the insulation layer is determined by the formula:

$$
\mathrm{d}=\sqrt{\frac{100 \cdot \lambda \cdot \mathrm{K}_{\mathrm{a}}}{\mathrm{K}_{\mathrm{O}} \cdot \mathrm{K}_{\mathrm{i}}}},
$$

where $\lambda$ - the thermal conductivity coefficient of the insulation;

$\mathrm{K}_{\mathrm{o}}$ - the heat transfer coefficient of the original structure. With an increase in the fixed part of one-time costs, the maximum of the coefficient A becomes less and less pronounced (the thickness of the heat-insulating layer has a lesser effect on economic efficiency than the cost of thermal insulation) and with too large a constant part of one-time costs (in this case, $\mathrm{K}_{\mathrm{a}}>100 \mathrm{marks} / \mathrm{m}^{2}, \mathrm{~A}<0.07$ ), the installation of additional thermal insulation becomes unprofitable.

In the conditions of a planned economy in the USSR, the minimum of reduced costs served as a criterion for the effectiveness of capital investments [2]. To select the option of capital investments, it was recommended to use the following formulas:

$$
\begin{aligned}
& \mathrm{P}_{\mathrm{i}}=\mathrm{K}_{\mathrm{i}}+\mathrm{T}_{\mathrm{n}} \cdot \mathrm{C}_{\mathrm{i}} \Rightarrow \min , \\
& \mathrm{P}_{\mathrm{i}}=\mathrm{C}_{\mathrm{i}}+\mathrm{E}_{\mathrm{n}} \cdot \mathrm{K}_{\mathrm{i}} \Rightarrow \min ,
\end{aligned}
$$

where $\mathrm{K}_{\mathrm{i}}$ - capital investment in the $\mathrm{i}$-th version;

$\mathrm{C}_{\mathrm{i}}$ - the cost price (current expenses) according to the $\mathrm{i}$-th version;

$\mathrm{T}_{\mathrm{n}}$ - the standard payback period for additional capital investments due to savings from lower current costs;

$E_{n}$ - the normative coefficient of efficiency of capital investments.

When choosing the optimal design solution for enclosing structures from the point of view of their heat-shielding qualities, it is necessary [3] to determine the economically feasible thermal resistance of the heat-insulating layer $\mathrm{R}^{\mathrm{ec}}{ }_{\mathrm{hi}}$ multi-layer enclosing structure or homogeneous (single-layer) by the formula: 


$$
R_{h i}^{e c}=\sqrt{\frac{\left(\mathrm{t}_{\mathrm{int}}-\mathrm{t}_{o t .}\right) \cdot \mathrm{Z}_{o t .} \cdot m \cdot C_{T} \cdot 1_{T}}{\lambda_{h i} \cdot C_{h i} \cdot E_{n . p .}}},
$$

where $\mathrm{t}_{\text {int }}$ - the design temperature of the internal air, ${ }^{0} \mathrm{C}$;

$\mathrm{t}_{\mathrm{ot}}$ - average outdoor temperature for the heating period, ${ }^{0} \mathrm{C}$;

$\mathrm{Z}_{\mathrm{ot}}$ - - duration of the heating period, $\mathrm{h} /$ year;

$\mathrm{m}$ - the coefficient taking into account additionally the heat loss due to infiltration of outside air;

$\mathrm{C}_{\mathrm{T}}$ - the cost of thermal energy rub./W;

$1_{\mathrm{T}}$ - coefficient taking into account the future rise in the cost of thermal energy;

$\lambda_{\text {hi }}$ - the calculated coefficient of thermal conductivity of the material of the insulating layer of a multilayer enclosing structure or a homogeneous structure;

$\mathrm{C}_{\mathrm{hi}}$ - - the cost of the material of the heat-insulating layer of a multi-layer enclosing structure or a homogeneous structure, rub. $/ \mathrm{m}^{3}$;

$E_{\text {n.p. }}$ - the standard for reducing costs at different times, 1/year.

The economically optimal thermal resistance of the $\mathrm{R}^{\mathrm{ec}}$ hi of enclosing structures should be taken on the basis of the condition of ensuring the lowest reduced costs $\mathrm{P}$, which are determined by the calculation for the variants of enclosing structures with different heat transfer resistance $\mathrm{R}_{\mathrm{o}}$ :

$$
\mathrm{P}=\mathrm{C}_{\mathrm{d}}+\frac{\left(\mathrm{t}_{\text {int }}-\mathrm{t}_{\mathrm{ot}}\right) \cdot \mathrm{Z}_{\mathrm{ot}} \cdot \mathrm{m} \cdot \mathrm{C}_{\mathrm{T}} \cdot \mathrm{l}_{\mathrm{T}}}{\mathrm{R}_{\mathrm{O}} \cdot \mathrm{E}_{\mathrm{np}}},
$$

where Cd - one-time costs (cost of construction and installation works), rub $/ \mathrm{m}^{2}$;

$\mathrm{R}_{\mathrm{o}}$ - thermal resistance of enclosing structures, taken for calculation options equal to and close to the value of heat transfer resistance, defined by the formula (9).

The assessment of the economic efficiency of additional thermal insulation of enclosing structures according to the above methods is carried out without taking into account the time factor (discounting) and saving money for heating during the operation of structures after the payback period.

In the book of Dmitriev A.N. [4] proposed a method for optimizing the level of thermal protection of enclosing structures, in which the optimality criterion is the maximum net profit from the saved thermal energy for the estimated term $\mathrm{N}$ of the fence with additional thermal insulation:

$$
\mathrm{S}(\mathrm{m})=\mathrm{P}(\mathrm{m}) \cdot \mathrm{N}-\mathrm{C}(\mathrm{m}),
$$

where $\mathrm{S}(\mathrm{m})$ - the net profit;

$P(m)$ - the cost of annually saved energy;

$\mathrm{C}(\mathrm{m})$ is the cost of installing an additional layer of thermal insulation, $\mathrm{m}$ is the rate of increase in the level of thermal protection of enclosing structures.

However, this method does not take into account the change in the value of money over time.

\section{Methods}

In connection with the action of market conditions, the method of comparing effective variants of technologies and investments by reduced costs does not reflect real economic indicators. At present, the assessment of the efficiency of insulation of residential and civil 
buildings should be conducted on the basis of calculations of economic indicators taking into account the time factor, i.e. discounting [5,6,7]. The most common are integral indicators: net present value (NPV), index of profitability of additional capital investments (ID), internal rate of return (IRR), payback period of additional capital investments, which are based on the concept of discounting.

Net present value (NPV) - an indicator that reflects the growth of values as a result of the project, because it represents the difference between the amount of cash receipts that arise during the implementation of the project and are reduced (discounted) to their present value, and the sum of the discounted values of all costs necessary for the implementation of the project. For projects on the installation of additional thermal insulation of enclosing structures, when investments are made at the very beginning of the project, and cash receipts (savings in payment for heating services) are the same in each period, the NPV formula will look like:

$$
\mathrm{NPV}=\mathrm{E} \cdot \frac{1-(1+\mathrm{r})^{-\mathrm{T}}}{\mathrm{r}}-\mathrm{K}
$$

where $\mathrm{E}$ - the annual savings in heating money due to the increase in thermal resistance of the enclosing structures;

$\mathrm{K}$ - capital costs for the device of additional thermal insulation;

$\mathrm{T}$ - the duration of the billing period; $\mathrm{r}$ is a constant discount rate equal to the rate of return on capital acceptable for an investor.

$$
\mathrm{E}=\left(\mathrm{t}_{\text {int }}-\mathrm{t}_{\mathrm{ot}}\right) \cdot \mathrm{Z}_{\mathrm{ot}} \cdot \mathrm{m} \cdot \mathrm{l}_{\mathrm{T}} \cdot \mathrm{C}_{\mathrm{T}} \cdot\left(\frac{1}{\mathrm{R}_{\mathrm{o}}}-\frac{1}{\mathrm{R}}\right),
$$

where $\mathrm{R}_{0}, \mathrm{R}$ is the thermal resistance of the enclosing structures, respectively, before and after the device of additional thermal insulation.

$$
\mathrm{K}=\mathrm{C}_{\mathrm{k}}+\delta_{\mathrm{hi}} \cdot \mathrm{C}_{\mathrm{hi}},
$$

where $C_{k}$ - the cost of the building envelope without taking into account the cost of the thermal insulation layer (the cost of performing work on the device of additional thermal insulation plus the cost of materials of the protective and finishing layer).

Dissemination of the method of evaluating the effectiveness of projects with the help of NPV is due to the ability to directly determine the effect of the project (its absolute value) for the billing period.

In figure 2 shows the dependence of the NPV on the thermal resistance of the enclosing structures and its optimal value.

\section{Results and Discussion}

Analytically optimal thermal resistance of the enclosing structures can be determined by differentiating equation (12) and equating it to zero:

$$
\frac{\partial(\mathrm{NPV})}{\partial(\mathrm{R})}=0 \text {. }
$$


After substitutions and calculation, we get:

$$
\mathrm{R}_{\text {opt }}=\mathrm{R}_{\mathrm{K}}+\delta_{\mathrm{hi}} / \lambda_{\text {hi. }}=\sqrt{\frac{\left(\mathrm{t}_{\text {int }}-\mathrm{t}_{0 . \mathrm{t}}\right) \cdot \mathrm{Z}_{\mathrm{ot}} \cdot \mathrm{m} \cdot \mathrm{C}_{\mathrm{T}} \cdot \mathrm{l}_{\mathrm{T}}}{\lambda_{\mathrm{hi}} \cdot \mathrm{C}_{\mathrm{hi}}} \times \frac{1-(1+\mathrm{r})^{-\mathrm{T}}}{\mathrm{r}}},
$$

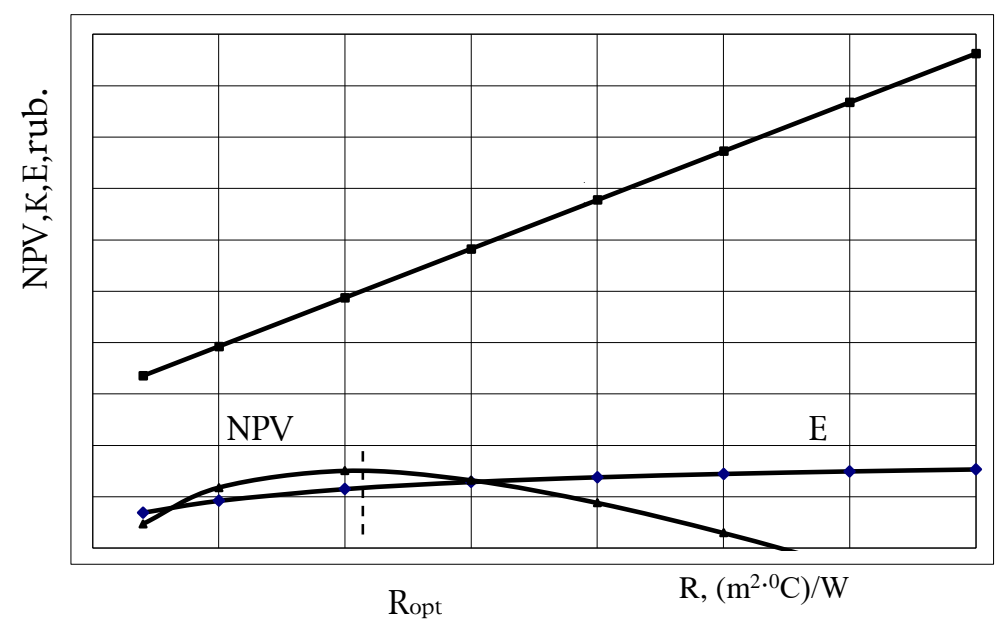

Fig. 2. The change in the NPV depending on the thermal resistance of the building envelope.

\section{Conclusion}

Thus, when determining the optimal level of thermal protection using formula (16), the entire period of operation of the building envelope is take into account. All costs and revenues are calculated taking into account the time factor, which completely eliminates the disadvantages of the above methods. Therefore, in the current economic conditions, the main indicators of the economic efficiency of projects for additional thermal insulation are indicators that are based on the principle of discounting.

The net discounted income of the project for the insulation of buildings depends mainly on the capital costs of additional thermal insulation, therefore it is necessary to reduce the capital costs of the thermal insulation device. That is why it is advisable to conduct a search for new, efficient and inexpensive domestic heat-insulating materials, effective technologies for thermal insulation, fastening elements and protective elements, ways of mechanization of work.

\section{References}

1. I.N. Butovsky, O.V. Hudozhina. Improvement of constructive solutions of a heatshielding of external walls of buildings. Review, 68 p. (1990).

2. M.P. Pedan, Construction economy: Studies for higher education institutions, 571 p. (1987).

3. Construction Norms and Regulations - II-3-79**. Construction heating engineer / the State Committee for Construction of the USSR. 32 p. ( 1986). 
4. A.N Dmitriyev, Management of energy saving innovations in construction of buildings: Manual, 320 p. (2000).

5. V.V. Kovalyov, Financial analysis: Management of the capital. Choice of investments. Analysis of the reporting. - 2nd prod., reslave and additional, 512p. (1997).

6. V.D. Shapiro, Project management. 610 p. (1996).

7. A. Borodinecs, J. Zemitis, J. Sorokins, D.V. Baranova, D.O. Sovetnikov, Mag. Civ. Eng., 8 (68), 58-64 (2016) doi: 10.5862/MCE.68.6

8. V.A. Verba, O.A. Zagorodnikh, Proyektny analysis: Pidruchnik, 322 p. (2000).

9. E.A. Statcenko, A.F. Ostrovaia, T.A. Musorina, M.I. Kukolev, M.R. Petritchenko, Mag. Civ. Eng., 8 (68), 86-91 (2016).

10. S.H. Bayramukov, Z.N. Dolaeva, Mag. Civ. Eng., 8 (76), 3-19 (2017).

11. A.E. Kiryudcheva, V.V. Shishkina, D.V. Nemova, Construction of Unique Buildings and Structures, 5 (44), 19-30 (2016)

12. D.O. Sovetnikov, D.O.Semashkina, D.V.Baranova, Construction of Unique Buildings and Structures, 12 (51), 7-19 (2016).

13. M.D Korovina, Construction of Unique Buildings and Structures, 11(62), 93-102 (2017).

14. D.N. Tseytin, N.I. Vatin, D.V. Nemova, P.P. Rymkevich, A.S. Gorshkov, Construction of Unique Buildings and Structures, 1 (40), 20-31 (2016)

15. T.A. Musorina, O.S. Gamayunova, M.R.Petrichenko, MGSU Bulletin, 11 (110), 12691277 (2017).

16. A.S. Gorshkov, N.I. Vatin, P.P. Rymkevich, O.O. Kydrevich, Mag. Civ. Eng., 2(78), 65-75 (2018).

17. D.D. Zaborova, M.I. Kukolev, T.A. Mussorina, M.R. Petritchenko. St. Petersburg State Polytechnic University Journal of Engineering Science and Technology, 4(254), 28-33 (2016).

18. E.S. Ivanova, A.S. Gorshkov, Construction of Unique Buildings and Structures, 4 (43), 58-72 (2016).

19. A.I. Kopylova, A.K. Bogomolova, D.V. Nemova, Construction of Unique Buildings and Structures, 10 (49), 20-34 (2016).

20. A. Gorshkov, N. Vatin, D. Nemova, A. Shabaldin, L. Melnikova, P. Kirill, Procedia Engineer., 117(1), 1085-1094 (2015).

21. N.I. Vatin, D.V. Nemova, A.S. Kazimirova, K.N.Gureev, Adv. Mat. Res., 953-954, 1537-1544 (2014).

22. N. Vatin, D. Nemova, L. Khazieva, D. Chernik, Appl. Mech. Mater., 635-637, 20572062 (2014)

23. M.R. Petritchenko, S.A. Subbotina, F.F. Khairutdinova, E.V. Reich, D.V. Nemova, V.Ya. Olshevskiy, V.V. Sergeev, Mag. Civ. Eng., 73 (5), 40-48 (2017)

24. N. Vatin, M. Petrichenko, D. Nemova, Appl. Mech. Mater., 633-634, 1007-1012 (2014)

25. A.S. Gorshkov, P.P. Rymkevich, N.I. Vatin, Mag. Civ. Eng., 52 (8), 38-48 and 65-66 (2014)

26. R. Alihodzic, V. Murgul, N. Vatin, E. Aronova, V. Nikolić, M. Tanić, D. Stanković, Appl. Mech. Mater., 624, 604-612 (2014).

27. A. Bolotin, V. Bakayev, J. Phys. Ther. Sci. (2017) 
28. V.A. Schegolev, O.V Novoseltsev, Teoriya i Praktika Fizicheskoy Kultury (2015) 